\title{
Synthesis of a Polymerizable Benzocyclobutene that Undergoes Ring-Opening Isomerization at Reduced Temperature
}

\author{
Coleen Pugh,* James S. Baker, William K. Storms \\ The University of Akron, Department of Polymer Science, Maurice Morton Institute of Polymer Science and Polymer Engineering, Akron, \\ OH 44325-3909, USA \\ Fax+1(330)9725290; E-mail: cpugh@uakron.edu \\ Received: 04.09.2013; Accepted: 12.09.2013
}

\begin{abstract}
Ethoxyvinylbenzocyclobutene is a substituted benzocyclobutene that undergoes radical polymerization to produce polymers that can be crosslinked at $100-150{ }^{\circ} \mathrm{C}$. The 4 - and 5-vinyl isomers are synthesized in a 1:4 ratio via a halogenated benzyne intermediate produced from anthranilic acid, followed by cycloaddition with ethyl vinyl ether and replacement of the halogen atom with a vinyl group.
\end{abstract}

Key words: benzocyclobutene, cycloaddition, ring-opening isomerization, Kumada coupling, benzyne

Bicyclo[4.2.0]octa-1,3,5-triene, or benzocyclobutene (BCB), ${ }^{1,2}$ has been widely used in polymer science based on the ring-opening ability of the strained cyclobutene ring. ${ }^{3}$ It is stable at room temperature, but undergoes an electrocyclic rearrangement at elevated temperature $\left(>200{ }^{\circ} \mathrm{C}\right)$ to the highly reactive $o$-quinodimethane. The $o$-quinodimethane undergoes Diels-Alder reactions, and in the absence of an external dienophile, generates 1,2,5,6-dibenzocyclooctane ( $25 \%)$ and higher oligomers $(\sim 75 \%)$ (Scheme 1$){ }^{4,5}$ Since the thermally unstable spirodimer does not generate any 1,2,5,6-dibenzocyclooctane upon heating, it apparently forms by a different mechanism than the oligomers. ${ }^{5}$ This thermal activation and the lack of condensation byproducts makes benzocyclobutene chemistry especially attractive for crosslinking ${ }^{6}$ and for polymer-forming reactions ${ }^{3}$ by a step (condensation-like) mechanism. Benzocyclobutene-containing vinyl monomers have also been polymerized by chain mechanisms. $^{7-10}$

Although the high temperature of the ring-opening isomerization reaction is useful for applications such as the crosslinking of engineering polymers, which are synthesized at elevated temperatures, it also limits the use of benzocyclobutene in other applications, such as those involving temperature-sensitive materials. For example, it would be difficult to exploit the benzocyclobutene crosslinking reaction to create nanostructured flexible films by field-assisted roll-to-roll processing if the glass transition temperature of the substrate polymer film and/or the available thermal field are significantly less than $200^{\circ} \mathrm{C}$. We are particularly interested in developing nanostructured flexible films using block copolymers that can be aligned

SYNLETT 2014, 25, 0148-0152

Advanced online publication: 21.11.2013

DOI: 10.1055/s-0033-1339925; Art ID: ST-2013-S0856-L

(C) Georg Thieme Verlag Stuttgart $\cdot$ New York and crosslinked at more reasonable temperatures than those used to crosslink benzocyclobutene.

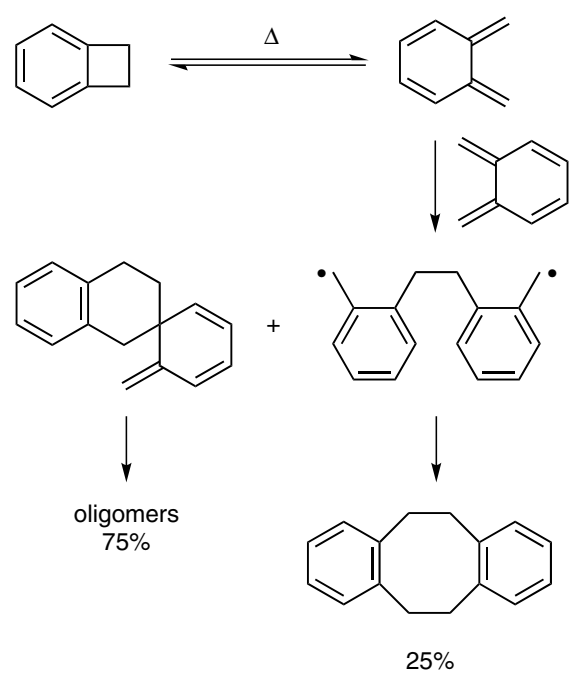

Scheme 1 Electrocyclic ring-opening of benzocyclobutene and its subsequent $[4+2]$ cycloaddition with another $o$-quinodimethane ${ }^{4}$

The ring-opening isomerization temperature of benzocyclobutenes can be lowered by introducing both electrondonating (raises the ground state energy) and electronwithdrawing (lowers the transition state energy) substituents onto the cyclobutene ring. ${ }^{5}$ For example, 1 -methoxybenzocyclobutene isomerizes at $\geq 110^{\circ} \mathrm{C},{ }^{11}$ and the cyclobutene rings of poly(1-benzocyclobutenyl vinyl ether) isomerize at $\geq 60{ }^{\circ} \mathrm{C}$. ${ }^{12}$ (The temperature range over which the exothermic isomerization transitions occur is usually broad.)

Block copolymers with controlled chain lengths are prepared by chain polymerizations, such as living anionic, cationic or radical polymerizations of vinyl monomers. ${ }^{13}$ Therefore, the preparation of well-defined block copolymers that can be aligned and crosslinked by benzocyclobutene chemistry at reduced temperatures requires the synthesis of a benzocyclobutene functionalized with both a polymerizable vinyl group, and a substituent that lowers the temperature of ring-opening isomerization, such as an ethyl ether moiety.

4-Vinylbenzocyclobutene (VBCB) was first synthesized by a Wittig reaction starting from 4-chloromethylbenzocyclobutene, ${ }^{8}$ and subsequently from 4-bromobenzocyclobutene with conversion into the corresponding 
benzaldehyde. ${ }^{7}$ It has also been synthesized by palladium(0)-catalyzed Heck coupling of 4-bromobenzocyclobutene with ethylene, ${ }^{14}$ by nickel(0)-catalyzed Kumada coupling of 4-bromobenzocyclobutene with vinyl bromide, ${ }^{9}$ and by palladium(0)-catalyzed coupling of 4-bromobenzocyclobutene with $\operatorname{tri}\left(n\right.$-butyl)vinyltin. ${ }^{15}$ Although 4-vinylbenzocyclobutene has been synthesized by several routes, there are no literature reports of the synthesis of 1-substituted 4-vinylbenzocyclobutenes.

Fuji holds a patent that uses 1-ethoxy-4-vinylbenzocyclobutene; ${ }^{16}$ however, its synthesis was not reported. An ether-substituted vinylbenzocyclobutene with an isomerization temperature at approximately $100{ }^{\circ} \mathrm{C}$ would be ideal for creating nanostructured flexible films, because many living chain polymerizations are performed at temperatures lower than $100{ }^{\circ} \mathrm{C}$, and $100-150{ }^{\circ} \mathrm{C}$ is accessible in field-assisted roll-to-roll processing equipment.

Our goal was therefore to introduce an ethoxy group onto the cyclobutene ring to decrease its isomerization temperature, and a halogen (Br or I) onto the aromatic ring to provide a site for attaching the polymerizable vinyl group. The most direct method for synthesizing 1-substituted benzocyclobutenes is by [2+2] cycloaddition of benzyne ${ }^{17}$ with an alkene, especially electron-rich alkenes such as vinyl ethers and vinyl acetate. ${ }^{18,19}$ Due to the many routes for converting 4-bromobenzocyclobutene into vinylbenzocyclobutene, ${ }^{7,9,14,15}$ we considered the three possible starting materials shown in Scheme 2 for synthesizing 4bromo-1-ethoxybenzocyclobutene via a benzyne intermediate. Since iodine exchanges faster than bromine in lithium-halogen exchange using $n$-butyllithium, ${ }^{20} 4$-bromo-2fluoroiodobenzene would be the most direct reagent for synthesizing 4-bromo-1-ethoxybenzocyclobutene if metal-iodine exchange with either $n$-butyllithium or possibly the Grignard reagent occurs selectively, thereby generating the benzyne by elimination of lithium fluoride $(\mathrm{LiF})$ or magnesium bromide fluoride $(\mathrm{MgBrF})$, respectively, in the presence of ethyl vinyl ether. However, the conver- sions were low. The Grignard halogen exchange was also not sufficiently selective, and we obtained several side products that were difficult to separate from the desired product. The Grignard route is not useful because the elimination step requires a higher temperature $\left(\geq 65^{\circ} \mathrm{C}\right)$ than the boiling point of ethyl vinyl ether (bp $33^{\circ} \mathrm{C}$ ).

We were able to synthesize 1-ethoxybenzocyclobutene by generating the benzyne in the presence of ethyl vinyl ether via either metallation-elimination starting from 2-bromofluorobenzene, or by first converting anthranilic acid into benzenediazonium-2-carboxylate using isoamyl nitrite in the presence of a catalytic amount of trifluoroacetic acid in tetrahydrofuran, ${ }^{21}$ followed by elimination of carbon dioxide and nitrogen; the Grignard route was not used because the elimination step required a higher temperature $\left(\geq 65^{\circ} \mathrm{C}\right.$ ) than the boiling point of ethyl vinyl ether.

Unfortunately, although benzocyclobutene is readily brominated using bromine in acetic acid, with only a minor amount of dealkylated (ring-opened) side product, ${ }^{22}$ the same conditions oxidize 1-ethoxybenzocyclobutene into benzocyclobutenone. For example, reaction of 1-ethoxybenzocyclobutene with 1.2 equivalents of bromine produced approximately equimolar amounts of benzocyclobutenone and unreacted 1-ethoxybenzocyclobutene. Other halogenation agents, such as $\mathrm{PhCH}_{2} \mathrm{NMe}_{3}^{+}, \quad \mathrm{ICl}_{2}{ }^{-} / \mathrm{ZnCl}_{2},{ }^{23-25} \quad \mathrm{PhCH}_{2} \mathrm{NMe}_{3}^{+}, \quad \mathrm{Br}_{3}^{-}$ $/ \mathrm{CaCO}_{3}{ }^{24}$ and $\mathrm{NH}_{4}^{+} \mathrm{I}^{-} / \mathrm{H}_{2} \mathrm{O}_{2}$ produced only a minor amount of side product with the remaining material unreacted. Therefore, the aromatic ring must be halogenated prior to functionalizing the cyclobutene ring. Note that although 2-(trimethylsilyl)aryl triflates ${ }^{26}$ generate arynes under very mild conditions, replacement of 4-bromo-2fluoroiodobenzene and 2-bromofluorobenzene, in Scheme 2, with a 2-silylaryl triflate will lead to the same problems for vinylation, either in the synthesis of the appropriately functionalized 2-silylaryl triflate, or in its use.

As outlined in Scheme 3, 1-ethoxyvinylbenzocyclobutene can be successfully synthesized by first regioselectively

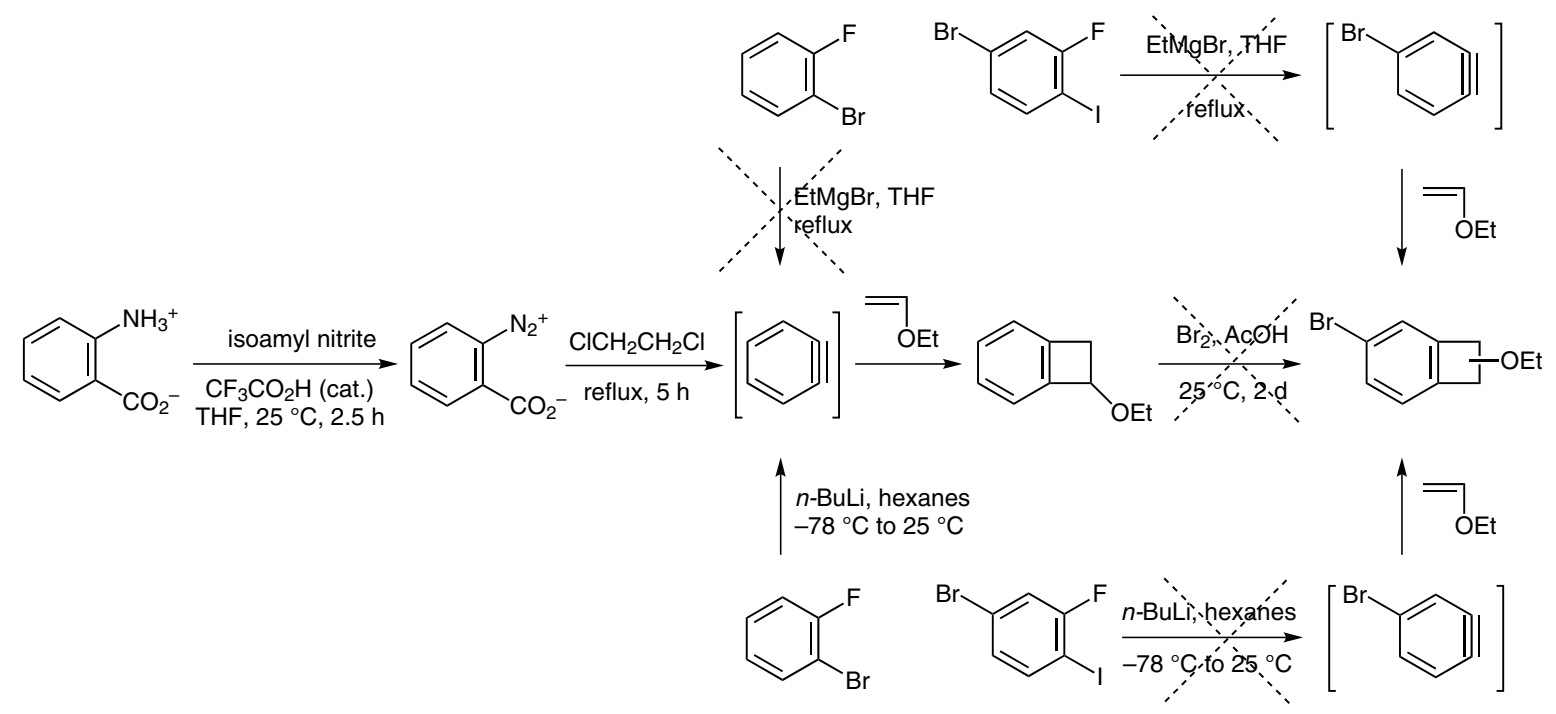

Scheme 2 Potential synthetic routes to 4- and/or 5-bromo-1-ethoxybenzocyclobutenes via benzyne intermediates 
iodinating anthranilic acid para to the amine group using ammonium iodide, similar to brominations using ammonium bromide,${ }^{27}$ in combination with hydrogen peroxide. The corresponding benzenediazonium-2-carboxylate ${ }^{28}$ is then generated using isoamyl nitrite, and converted into the iodinated benzyne at reflux in 1,4-dioxane or 1,2-dichloroethane in the presence of ethyl vinyl ether. Generation of the benzyne intermediate is the yield-limiting step, both because of the lower yields of halogenated benzenediazonium-2-carboxylates, ${ }^{29}$ and due to the low boiling point of ethyl vinyl ether. 1-Ethoxy-4-vinylbenzocyclobutene and 1-ethoxy-5-vinylbenzocyclobutene are produced in approximately a 1:4 ratio using either a two-step Wittig reaction, ${ }^{7}$ or by a direct Kumada coupling with vinyl bromide ${ }^{30}$ as the final step. ${ }^{31}$ Figure 1 presents the ${ }^{1} \mathrm{H}$ NMR spectrum of 1-ethoxy-5-vinylbenzocyclobutene produced by the Kumada coupling route and isolated from its product mixture with 1-ethoxy-4-vinylbenzocyclobutene. The resonance at $5.04 \mathrm{ppm}$ corresponds to the methine proton, and those at 3.10 and $3.44 \mathrm{ppm}$ correspond to the methylene protons of the benzocyclobutene ring.

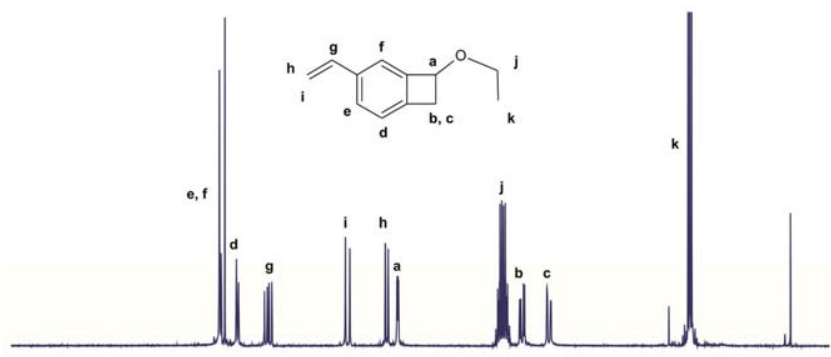

Figure $1{ }^{1} \mathrm{H}$ NMR $\left(500 \mathrm{MHz}, \mathrm{CDCl}_{3}\right)$ spectrum of 1-ethoxy-5-vinylbenzocyclobutene synthesized by, and isolated from, the Kumada coupling of 1-ethoxy-4-iodobenzocyclobutene and 1-ethoxy-5-iodobenzocyclobutene with vinyl bromide
The resulting 1-ethoxyvinylbenzocyclobutene can be polymerized by conventional or living radical polymerizations. For example, copolymerization of an 8:2 mixture of styrene and 1-ethoxyvinylbenzocyclobutene by atom transfer radical polymerization (ATRP), using methyl 2bromopropionate as the initiator and copper(I) bromidetris[2-(dimethylamino)ethyl]amine $\left(\mathrm{CuBr}-\mathrm{Me}_{6} \mathrm{TREN}\right)$ as the catalyst system at $60^{\circ} \mathrm{C}$, produced poly(styrene-co-1ethoxyvinylbenzocyclobutene $)\left(M_{\mathrm{n}}=5.50 \times 10^{4} \mathrm{~g} / \mathrm{mol}\right.$ and pdi $=1.41)$ in $43 \%$ purified yield. The first differential scanning calorimetry (DSC) heating scan presented in Figure 2 demonstrates that this copolymer exhibits a glass transition at $\sim 100^{\circ} \mathrm{C}$, followed by a broad exotherm with a maximum at $135^{\circ} \mathrm{C}$ due to ring-opening isomerization and crosslinking. Due to crosslinking, this material exhibits only a glass transition temperature at $116{ }^{\circ} \mathrm{C}$ on the second and third heating scans.

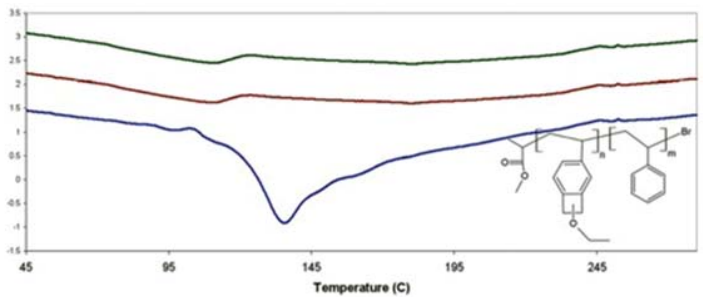

Figure 2 Normalized DSC traces $\left(10{ }^{\circ} \mathrm{C} / \mathrm{min} ; 1^{\text {st }}\right.$ heating: blue, $2^{\text {nd }}$ heating: red, $3^{\text {rd }}$ heating: green) of poly(styrene-co-1-ethoxyvinylbenzocyclobutene) $(80: 20 \mathrm{~mol} \%$ feed ratio $) ; M_{\mathrm{n}}=5.50 \times 10^{4} \mathrm{~g} / \mathrm{mol}$, pdi $=1.41$

In summary, we have established a synthetic route to 1ethoxyvinylbenzocyclobutene. 1-Ethoxyvinylbenzocyclobutene is a polymerizable benzocyclobutene that undergoes ring-opening isomerization and crosslinking at 100 $150{ }^{\circ} \mathrm{C}$, which is $\sim 100^{\circ} \mathrm{C}$ lower than that of the unsubstituted vinylbenzocyclobutene-containing polymers. The vinyl group was introduced via a halogen functionality,
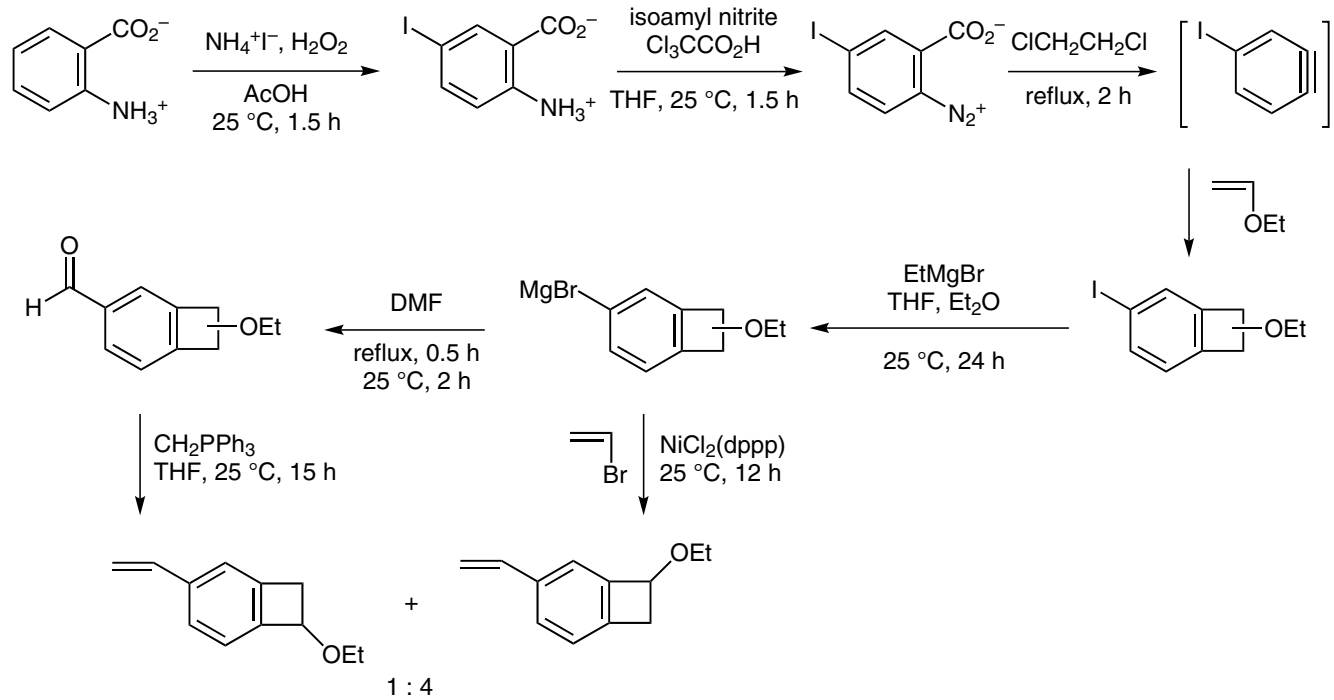

Scheme 3 Synthesis of 4- and 5-vinyl-1-ethoxybenzocyclobutene (1:4 ratio) by first halogenating anthranilic acid 
which must be introduced to the aromatic ring before forming the functionalized benzocyclobutene ring.

\section{Acknowledgment}

We acknowledge the National Science Foundation for support of this research through DMR-1006195 and a Special Creativity Award. We also gratefully acknowledge the Ohio Board of Regents for a partial matching award.

Supporting Information for this article is available online at http://www.thieme-connect.com/ejournals/toc/synlett.

\section{References and Notes}

(1) Cava, M. P.; Napier, D. R. J. Am. Chem. Soc. 1956, 78, 500

(2) For a review, see: Thummel, R. P. Acc. Chem. Res. 1980, 13, 70.

(3) For reviews, see: (a) Kirchhoff, R. A.; Carriere, C. J.; Bruza, K. J.; Rondan, N. G.; Sammler, R. L. J. Macromol. Sci. Chem., A 1991, 28, 1079. (b) Kirchhoff, R. A.; Bruza, K. J. Prog. Polym. Sci. 1993, 18, 85. (c) Kirchhoff, R. A.; Bruza, K. J. CHEMTECH 1993, 23, 22. (d) Hahn, S. F.; Rondan, N. G. In Polymeric Materials Encyclopedia; Vol. 1; CRC Press: Boca Raton, 1995, 453.

(4) Jensen, F. R.; Coleman, W. E.; Berlin, A. J. Tetrahedron Lett. 1962, 15 .

(5) Segura, J. L.; Martín, N. Chem. Rev. 1999, 99, 3199.

(6) (a) Wong, P. K. US Patent 4708994, 1987; Chem. Abstr. 1988, 108, 132792. (b) Wong, P. K. US Patent 4776180 , 1988; Chem. Abstr. 1987, 107, 177818. (c) Walker, K. A.; Markoski, L. J.; Moore, J. S. Macromolecules 1993, 26, 3713. (d) Deeter, G. A.; Venkataraman, D.; Kampf, J. W.; Moore, J. S. Macromolecules 1994, 27, 2647.

(7) Harth, E.; van Horn, B.; Lee, V. Y.; Germack, D. S.; Gonzales, C. P.; Miller, R. D.; Hawker, C. J. J. Am. Chem. Soc. 2002, 124, 8653.

(8) (a) Wong, P. K. US 4698394, 1987; Chem. Abstr. 1988, 108, 6630. (b) Wong, P. K. US Patent 4722974, 1988; Chem. Abstr. 1988, 108, 6630.

(9) Endo, T.; Chino, K.; Koizumi, T.; Takata, T. J. Polym. Sci., Polym. Chem. Ed. 1995, 33, 707.

(10) (a) Chino, K.; Takata, T.; Endo, T. Macromolecules 1995, 28, 5947. (b) Chino, K.; Takata, T.; Endo, T. J. Polym. Sci., Polym. Chem. Ed. 1999, 37, 1555. (c) Chino, K.; Endo, T. J. Polym. Sci., Polym. Chem. Ed. 2000, 38, 3434. (d) Sakellariou, G.; Baskaran, D.; Hadjichristidis, N.; Mays, J. W. Macromolecules 2006, 39, 3525.

(11) Chino, K.; Takata, T.; Endo, T. Macromolecules 1997, 30 , 6715.

(12) Chino, K.; Takata, T.; Endo, T. J. Polym. Sci., Polym. Chem. Ed. 1999, 37, 59.

(13) Taton, D.; Gnanou, Y. In Block Copolymers in Nanoscience; Lazzari, M.; Liu, G.; Lecommandoux, S., Eds.; Wiley-VCH: Weinheim, 2006, 9-35.

(14) Kirchhoff, R. A.; Schrock, A. K.; Hahn, S. F. US Patent 4724260, 1988; Chem. Abstr. 1988, 108, 95095.

(15) Blomberg, S.; Ostberg, S.; Harth, E.; Bosman, A. W.; van Horn, B.; Hawker, C. J. J. Polym. Sci., Polym. Chem. Ed. 2002, 40, 1309.

(16) Makino, N.; Oohashi, H. US Patent 6780567 B2, 2004; Chem. Abstr. 2013, 1620468.
(17) For a review on arynes, see for example: Tadross, P. M.; Stolz, B. M. Chem. Rev. 2012, 112, 3550.

(18) See for example: (a) Klundt, I. L. Chem. Rev. 1970, 70, 471. (b) Thummel, R. P. Acc. Chem. Res. 1980, 13, 70.

(19) Wasserman, H. H.; Solodar, J. J. Am. Chem. Soc. 1965, 87, 4002.

(20) Cooke, M. P.; Widener, R. K. J. Org. Chem. 1987, 52, 1381.

(21) Logullo, F. M.; Seitz, A. H.; Friedman, L. Org. Synth. 1968, $48,12$.

(22) Lloyd, J. B. F.; Ongley, P. A. Tetrahedron 1965, 21, 2457.

(23) (a) Kajigaeshi, S.; Kakinami, T.; Yamasaki, H.; Fujisaki, S.; Kondo, M.; Okamoto, T. Chem. Lett. 1987, 2109. (b) Kajigaeshi, S.; Kakinami, T.; Moriwaki, M.; Watanabe, M.; Fujisaki, S.; Okamoto, T. Chem. Lett. 1988, 795.

(24) Kajigaeshi, S.; Kakinami, T.; Moriwaki, M.; Tanaka, T.; Fujisaki, S.; Okamoto, T. Bull. Chem. Soc. Jpn. 1989, 62, 439.

(25) Pugh, C.; Dharia, J.; Arehart, S. V. Macromolecules 1997, 30,4520 .

(26) Himeshima, Y.; Sonoda, T.; Kobayashi, H. Chem. Lett. 1983, 1211.

(27) Mohan, K. V. V. K.; Narender, N.; Srinivsu, P.; Kulkarni, S. J.; Raghavan, K. V. Synth. Commun. 2004, 34, 2143.

(28) CAUTION: Benzenediazonium-2-carboxylates can react explosively to shock, scraping, or heating when dry. These compounds must remain wet with solvent. Reactions using benzenediazonium-2-carboxylate reagents are most safely performed in a Parr reactor

(29) Stiles, M.; Miller, R. G.; Burckhardt, U. J. Am. Chem. Soc. 1963, 85, 1792.

(30) (a) Tamao, K.; Sumitani, K.; Kumada, M. J. Am. Chem. Soc. 1972, 94, 4374. (b) Tamao, K.; Sumitani, K.; Kiso, Y.; Zembayashi, M.; Fujioka, A.; Kodama, S.; Nakajima, I.; Minato, A.; Kumada, M. Bull. Chem. Soc. Jpn. 1976, 49, 1958. (c) Kajigaeshi, S.; Kakinami, T.; Tokiyama, H.; Hirakawa, T.; Okamoto, T. Chem. Lett. 1987, 627. (d) Shimomura, O.; Sato, T.; Tomita, I.; Suzuki, M.; Endo, T. J. Polym. Sci., Polym. Chem. Ed. 1997, 35, 2813.

(31) 4- and 5-Vinyl-1-ethoxybenzocyclobutene via Kumada Coupling

1-Ethoxyvinylbenzocyclobutene was prepared via a Kumada coupling in 50-75\% yield as in the following example. A solution of iodinated 1-ethoxybenzocyclobutene (3.7 g, $14 \mathrm{mmol} ; 1: 4$ ratio of the 4 - and 5-iodo isomers) in anhydrous $\mathrm{Et}_{2} \mathrm{O}(20 \mathrm{~mL})$ was added dropwise over $30 \mathrm{~min}$ to $\mathrm{Mg}$ turnings $(0.35 \mathrm{~g}, 14 \mathrm{mmol})$ in anhydrous THF $(25 \mathrm{~mL})$ at r.t. The solution was stirred at r.t. until ${ }^{1} \mathrm{H}$ NMR analysis of $\mathrm{MeOH}$-quenched aliquots confirmed that the formation of the Grignard reagent was complete $(18 \mathrm{~h})$. The solution was then transferred to the glass sleeve of a Parr reactor, followed by the addition of $\mathrm{Ni}(\mathrm{dppp}) \mathrm{Cl}_{2}(20 \mathrm{mg}, 37 \mu \mathrm{mol})$ and vinyl bromide $(2.0 \mathrm{~g}, 19 \mathrm{mmol})$. After stirring at r.t. for $12 \mathrm{~h}$, the mixture was neutralized with $2 \%$ aq $\mathrm{HCl}(50 \mathrm{~mL})$ and then extracted with $\mathrm{Et}_{2} \mathrm{O}(3 \times 25 \mathrm{~mL})$. The combined organic layers were washed with sat. aq $\mathrm{NaHCO}_{3}$ solution $(2 \times 30$ $\mathrm{mL})$ and $\mathrm{H}_{2} \mathrm{O}(30 \mathrm{~mL})$, and dried over $\mathrm{MgSO}_{4}$. The product was purified ${ }^{32}$ by column chromatography using silica gel as the stationary phase (hexanes- $\mathrm{Et}_{2} \mathrm{O}, 4: 1, R_{f}=0.60$ ) to yield $1.5 \mathrm{~g}(64 \%)$ of a colorless oil composed of a 1:4 ratio of the 4- and 5-vinyl-1-ethoxybenzocyclobutene isomers.

5-Vinyl-1-ethoxybenzocyclobutene

${ }^{1} \mathrm{H}$ NMR $\left(300 \mathrm{MHz}, \mathrm{CDCl}_{3}\right): \delta=1.29\left(\mathrm{t},{ }^{3} J=7.0 \mathrm{~Hz}, 3 \mathrm{H}\right.$, $\left.\mathrm{CH}_{3}\right), 3.10\left(\mathrm{dd},{ }^{2} \mathrm{~J}=14.4 \mathrm{~Hz},{ }^{3} \mathrm{~J}=1.6 \mathrm{~Hz}, 1 \mathrm{H}, \mathrm{CHHAr}\right), 3.44$ $\left(\mathrm{dd},{ }^{2} J=14.4 \mathrm{~Hz},{ }^{3} J=4.4 \mathrm{~Hz}, 1 \mathrm{H}, \mathrm{CH} H \mathrm{Ar}\right), 3.66\left(\mathrm{dq},{ }^{2} J=\right.$ $\left.9.1 \mathrm{~Hz},{ }^{3} J=7.0 \mathrm{~Hz}, 1 \mathrm{H}, \mathrm{OCH} \mathrm{H}\right), 3.73\left(\mathrm{dq},{ }^{2} J=9.1 \mathrm{~Hz},{ }^{3} J=\right.$ 
$7.0 \mathrm{~Hz}, 1 \mathrm{H}, \mathrm{OCHH}), 5.04\left(\mathrm{dd},{ }^{3} J=4.4 \mathrm{~Hz},{ }^{3} J=2.0 \mathrm{~Hz}, 1 \mathrm{H}\right.$, $\mathrm{C} H \mathrm{OEt}), 5.18\left(\mathrm{dd},{ }^{3} J_{\mathrm{BX}}=10.9 \mathrm{~Hz},{ }^{2} J_{\mathrm{AB}}=0.8 \mathrm{~Hz}, 1 \mathrm{H}\right.$,

$\left.\mathrm{HCH}_{\mathrm{B} \text { trans }}=\right), 5.68\left(\mathrm{dd},{ }^{3} J_{\mathrm{AX}}=17.6 \mathrm{~Hz},{ }^{2} J_{\mathrm{AB}}=0.9 \mathrm{~Hz}, 1 \mathrm{H}\right.$, $\left.\mathrm{HC} H_{\mathrm{A}, c i s}=\right), 6.70\left(\mathrm{dd},{ }^{3} J_{\mathrm{AX}}=17.6 \mathrm{~Hz},{ }^{3} J_{\mathrm{BX}}=10.9 \mathrm{~Hz}, 1 \mathrm{H}\right.$, $\left.\mathrm{CH}_{\mathrm{X}}=\right), 7.09\left(\mathrm{~d},{ }^{3} J_{\text {ortho }}=8.4 \mathrm{~Hz}, 1 \mathrm{H}\right.$, aromatic $\left.\mathrm{C} 3 \mathrm{H}\right), 7.24(\mathrm{~s}$, aromatic $\mathrm{C} 6 H), 7.35\left(\mathrm{~d},{ }^{3} J_{\text {ortho }}=8.5 \mathrm{~Hz}, 1 \mathrm{H}\right.$, aromatic $\left.\mathrm{C} 4 H\right)$.
Anal. Calcd for $\mathrm{C}_{12} \mathrm{H}_{14} \mathrm{O}: \mathrm{C}, 82.72 ; \mathrm{H}, 8.10$. Found: $\mathrm{C}, 82.46$; $\mathrm{H}, 8.11$.

(32) Alternatively, an inhibitor such as pyrogallol can be added to the crude product, which can then be purified by distillation at $77^{\circ} \mathrm{C} / 1 \mathrm{mmHg}$. 